\title{
LOGICA ESCLAVISTA Y RESISTENCIA NEGRA EN LOS ANDES ECUATORIANOS A FINALES DEL SIGLO XVIII
}

\author{
POR \\ BERNARD LAVALLE \\ Maison des Pays Iberiques. Burdeos
}

En el norte de la república del Ecuador, la orografía andina presenta una característica relativamente original: un largo valle transversal, que corre grosso modo en la dirección surestenoroeste. Nacido a unos 3.000 metros de altura en las faldas de la cordillera oriental, el río que lo riega se llama primero el río Blanco, luego, nutrido por diversos afluentes, el Mataquí. Sin embargo, en la mayor parte de su curso - aunque conocido popularmente en la zona como el Río Grande- se denomina oficialmente el Chota y, después de su unión con el Piguchuela, el Mira que, atravesando por impresionantes desfiladeros la cordillera occidental a unos 1.200 metros, va a perderse rumbo al litoral del Pacífico.

En su parte central, el Chota-Mira articula una cuenca de unos $80 \mathrm{~km}^{2}$ de los que se cultivan aproximadamente 3.000 hectáreas situadas entre 1.200 y 3.000 metros. Son, según su localización, tierras de regadío -dada la sequía dominante en el centro del valle- o, en las faldas de éste, terrenos que aprovechan en grado variable la humedad natural proveniente de las alturas circundantes.

A partir de la llegada de los españoles, se inició en aquella zona una serie de relevantes cambios económicos y, por lo tanto, ecológicos. Estos culminaron en los siglos XVII y XVIII cuando los jesuitas, a partir de 1610, pero con más intensidad entre 1680 y 1740, consiguieron allí una posición dominante y se constituyeron poco a poco - con los acostumbrados e inacabables conflictos de tierras y sobre todo de aguas- uno de los grandes conjuntos

Sigla UTILIZADA:

ANHQ: Archivo Nacional de Historia, Quito. 
territoriales que caracterizaron su asentamiento en la América española. De las diecinueve unidades de producción que, antes de su expulsión, llegó a poseer la Cumpañía en los territorios de la Audiencia de Quito, cinco eran obrajes y catorce haciendas y/o estancias. De estas últimas, once estaban ubicadas en el valle o en las zonas aledañas (1), lo que basta para demostrar el peso de esa comarca en los intereses quiteños de los jesuitas.

Dadas las condiciones de clima y suelos, en las partes bajas del valle se dieron varias clases de cultivos: cocales, viñedos, algodonales, frutales, cereales y, en los páramos, ganadería tanto para el consumo interno como para la fuerza de trabajo y la venta. Pero, a partir de 1680, los padres de la Compañía especializaron la región en la caña de azúcar - a la que dedicaron nueve de sus haciendas- $y$, sin desechar nunca la mano de obra indigena cada vez más escasa, en la segunda mitad del XVII se convirtieron en grandes comerciantes negreros y dueños de numerosos esclavos, gracias a la fuerte liquidez de su capacidad financiera y a su sentido organizativo. En 1780, se calculaba en 2.615 el número total de los esclavos de todas las edades entonces residentes en las haciendas cañeras que habían sido de los padres (2). El valle del Chota-Mira, todavía hoy con una población predominantemente de origen africano, se convirtió así en el "valle de los negros", como se lo conoce en la zona situada más al sur de la que dependía administrativamente en tiempos coloniales, esto San Miguel de Ibarra y Otavalo.

Paralelamente a lo que hicieron Macera, Mörner, Tovar, etc. para otras exprovincias de la Compañía, la historia de esas haciendas ya se ha emprendido desde hace tiempo, primero en la perspectiva global de las propiedades jesuitas en el virreinato de Nueva Granada o en la Audiencia de Quito (3) y, más recientemente, con un enfoque más preciso de historia regional (4). El propósito de nuestras páginas no es añadir un capítulo a estos estudios ni, fundamentalmente, analizar los cambios sustanciales

(1) Rosario CORONEl. Feióo, El valle sangriento, de los indigenas de la coca y el algodón a la hacienda cañera jestita (1580-1700), Quito, FLÁCSO. Abya Yala, 1991, pág. 148.

(2) Idèm, pág. 88.

(3) Germán Colmenaris, Las haciendas jesuitas en el virreinato de Nueva Granada durante el siglo XVIII, Bogotá, Univ. Nac. de Colombia 1969, y CusHNitr (Nicolas), Farm and factorv. The Jessuits and the development of agrariani capitalism in colonial Quito, 1600)-1767, Stony Brook, Univ., of New York Press, 1982.

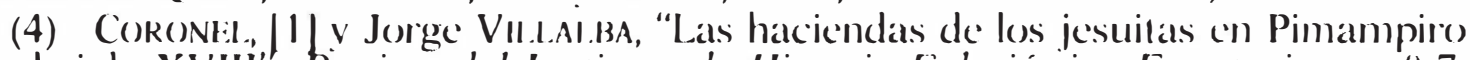

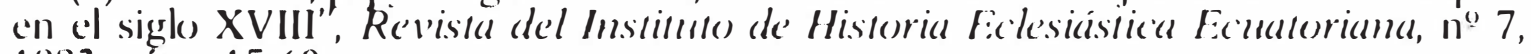
1983, pâgs. 15-60. 
que, desde muchos puntos de vista, conocieron dichas propiedades cuando, tras la "expatriación" de 1767, pasaron primero a la administración de las Temporalidades y después, entre 1783 y 1802, fueron rematadas en particulares. Además, como buena parte de lo que se va a leer versa sobre "rebeliones» de negros, tampoco es de creer que hemos querido completar para éstos el trabajo ya clásico de Segundo Moreno Yáñez (5).

Nuestro objetivo es diferente. Estas páginas han sido redactadas al mismo tiempo y con la misma intención - si bien a partir de otro tipo de documentación- que otro estudio publicado paralelamente a éste (6). En ambos hemos querido analizar cómo, a finales del XVIII y comienzos del siglo siguiente, cuando, por razones diversas, la presión de los amos sobre los esclavos se hizo mayor y más compulsiva, éstos, por lo menos a veces, lejos de quedar sin reacción ante la nueva situación, expresaron de diversas maneras, legales y/o violentas, que ya no estaban dispuestos a aceptarlo todo como antes. Tanto sus gestiones y alegatos, en algunos casos, como su comportamiento, en otros, pero también el eco que éstos tuvieron en ciertos ámbitos del poder político en Quito, parecen demostrar que, aunque todavía imperante, la esclavitud vivida por los negros así como la imagen que desde fuera se tenía de ella estaban experimentando modificaciones significativas, reveladoras o anunciadoras de otros tiempos en el camino todavía largo de la desaparición de este sistema económico-social.

\section{La CONCEPCIÓN (1778). LOS ESCLAVOS APELAN A LA JUSTICIA}

Según los archivos quiteños, el primer caso de problemas internos de cierta gravedad y envergadura en las antiguas haciendas jesuitas del Chota-Mira a cargo ya de la administración de las Temporalidades, se dio a comienzos de 1778, o sea prácticamente a los diez años de la salida forzosa de los padres de la Compañía.

Ocurrió en la hacienda de la Concepción, lo cual no fue quizás una casualidad. En efecto, ésta, situada en la parte más

(5) Segundo Morlino Yáñez, Sublevacionés indigenas én la Audiencia de Quito desde comienzos del sighlo XVII haska finales de la colonia, Quito, Universidad Católica 1977.

(6) Bernard Laval.1.: "Aquella ignominiosa herida que se hizo a la humanidad: el cuestionamiento de la esclavitud en Quito a finales del siglo XVIII" (trabajo en preparación). 
baja y favorable del valle - a tan sólo unos 1.400 metros- era, y con mucho, la más importante del gran complejo agrícola allí creado por los padres. Pocos años antes de los hechos aquí referidos (1776) se calculaba que, con 380 piezas, la Concepción reunia más de la cuarta parte de los esclavos que la Compañía había poseído en sus unidades de producción de la zona, y cuando la administración de las Temporalidades remató dichas haciendas y estancias, la Concepción fue adjudicada en 1789 a D. Juan A. Chiriboga por 180.000 pesos, mientras que las otras seis - pues se desconoce el valor de la hacienda Caldera- superaban escasamente en total los 290.000 pesos (7). Hacia finales de enero de 1778, pues, tres negros de la hacienda acompañados por sus respectivas esposas y liderados por Pedro Pascual Lucumín se encaminaron hacia Quito, por supuesto sin permiso, para quejarse de su situación directamente ante la justicia de la Audiencia. Es de notar que este recurso no procedía de una iniciativa individual o de un grupo reducido. Al contrario, Lucumín y sus acompañantes insistieron en que se hacía "en conjunta de todos los morenos de la hazienda». En Quito, denunciaron el "total maltrato" que recibían del administrador de la hacienda, Francisco Aurrecoechea. Mal alimentados, peor vestidos, obligados a un trabajo excesivo que incluía también domingos y días de fiesta hasta el mediodía cuando, excepcionalmente, en esas ocasiones se les podía exigir dos horas de faena. En fin, por si fuera poco, solían ser castigados con gran rigor.

Por esos años, en Quito, no era excepcional que los esclavos acudiesen personalmente ante la Justicia, pero lo hacían con bastante frecuencia, por motivos muy diversos, sobre todo aquellos que vivían en las ciudades y tenían por consiguiente facilidades evidentes para recurrir a ella (8).

Apenas sabedor de la iniciativa de "sus" esclavos - a los que calificú inmediatamente de fugados- el administrador de la Con-

(7) CORONEL [1], págs. 88 y 150.

(8) Véase el estudio citado en la nota 6. Anthony McFarlane encontró en haciendas que habian sido de los jesuitas en Nueva Granada casos similares al que estudiamos. En 1773, cuatro esclavos de la hacienda Villavieja, en la provincia de Neiva, llegaron hasta Bogotá para quejarse ante el virrey de los abusos que estaban padeciendo y en 1780, lo mismo sucedió en otra hacienda de la región de Cúcuta. Anthony McFarlane, "Cimarrones y palenques en Colombia, siglo XVIII", Historia y espacio (Cali), no 14, junio 1991, págs. 53-78, en particular págs. 73-75. De la misma forma, en 1786, en la costa peruana, 22 esclavos de la hacienda de Motocachi, que también había sido de los padres, intentaron ir a Lima para denunciar a su amo, Wilfredo Kapsol. E. Sublevaciones de esclavos en el Perii, siglo XVIII, Lima, Universidad R. Palma, 1975, pág. 73. 
cepción reaccionó vivamente y escribió el 26 de enero a la Audiencia. Pidió al presidente de Quito que se le concediese nada menos que el envío de doce soldados cuva misión consistiría en despachar hacia otras haciendas de la región pertenecientes también a la administración de las Temporalidades a algunos esclavos de la Concepción. Según Aurrecoechea, había en dicha hacienda demasiados esclavos "que aquí sobran». Si, efectivamente, por aquellos años el número de éstos fue aumentando en las propiedades que habian sido de los padres expatriados - globalmente su población esclava ganó 265 personas entre 1767 y 1780 (9)- ésta no parece haber sido la verdadera motivación del administrador.

Este quería, a manera de castigo y escarmiento, «trasponer a los huydos" esto es deportar a los que consideraba como cabecillas y fermentos de posibles disturbios venideros, separarlos de sus familias y amigos a los que se demostraría, de paso, la inutilidad de cualquier demanda del tipo de la que se había elevado hasta Quito. Además, la medida prevista ayudaría a disociar el grupo de los esclavos que, según se trasluce del texto de Aurrecoechea, era bastante unido y solidario («entre ellos se hacen alto por ser todos muy emparentados"). Si bien el administrador no ocultaba este aspecto de la situación, insistía también en otro que imaginaba convincente ante los altos funcionarios de la Audiencia preocupados por el descenso de la rentabilidad en las propiedades jesuitas: el trabajo -y por lo tanto la productividad de la hacienda- dejaba que desear. De las cien negras paleras, tan sólo cuarenta acudian regularmente a las faenas...

La respuesta del presidente D. Josef Diguja no se hizo esperar. El 31 de enero, o sea menos de una semana después, escribió a Aurrecoechea una carta llena de reproches, sin duda fruto de un primer y rápido examen del problema. Se negó a enviarle los soldados pedidos, ni tampoco se le autorizó a trasladar, aún sin la ayuda de la fuerza pública, a los esclavos "huidos», a no ser que se repitiesen en la hacienda amagos de disturbios. Esta última amenaza, evidentemente, tenía como objeto demostrar a los esclavos que, mientras la Justicia estudiaba su demanda, no se les permitiría ningún tipo de reacción sospechosa en contra de los fundamentos del orden esclavista. Al mismo tiempo, se mandó al controvertido administrador una tarifa, esto es un reglamento del trabajo y tratamiento de los esclavos, que habría

(9) CokONI:I. |1 |, päg. 116. 
de ser notificada a éstos y permanecería pegada en un lugar público de la hacienda.

En adelante, cada día, los esclavos tendrian a su cargo una faena bien precisa que correspondia a 40 guachas en invierno, de 50 a 60 en verano. Los domingos, para dejarles el tiempo de barrer sus casas, no se les podría llamar a trabajar antes de las seis de la mañana, y cuando terminasen sus faenas podrían utilizar las palas de la hacienda en las pequeñas parcelas (chacras) que se les permitía cultivar para su uso personal, y se los autorizaba a vender los plátanos que alli producian (10).

La tarifa precisaba también que se debería dar miel a las mujeres recién paridas, que los hombres seguirian recibiendo la acostumbrada ración de alcohol de caña (cachaza), que a cada esclavo se le daría semanalmente un almud de maíz, que las mujeres encinta no trabajarían durante los últimos tres meses de su embarazo, que las madres de mellizos serían dispensadas de faenas durante cierto tiempo suplementario, etc. Esta tarifa no aportaba en realidad ninguna novedad, pero su nueva publicación en la hacienda tenía el doble mérito de limitar los posibles abusos de Aurrecoechea como la tentación, por parte de los esclavos, de zafarse de siquiera parte de su obligación. En efecto, era conocido de todos que, desde que habían pasado a poder de las Temporalidades, la rentabilidad de las haciendas de los expatriados como la eficiencia y dedicación al trabajo de los esclavos habían bajado de forma sustancial.

Los seis esclavos "huidos" a Quito comparecieron formalmente ante la Justicia el 11 de febrero, fecha en la que se inició el estudio a fondo del problema que planteaban. La instrucción del sumario duró hasta el 11 de abril y, casi inmediatamente después, Aurrecoechea fue sentenciado a una multa de 200 pesos a los

(10) El goce de dichas parcelas no era mera filantropía por parte de los amos. Fuera de que el esclavo encontraba en ellas un suplemento para su alimentación, se solía considerar que las chacras tenían la virtud de mantener al esclavo ocupado aún fuera de las faenas que le eran impuestas que le vinculaban más con la hacienda, disminuyendo así la tentación de la fuga. Nótese la diferencia con lo que había pasado algunos antes en el Perú. Allí, en 1768, ante el descenso de la productividad, la administración de las Temporalidades había prohibido la entrega de chacras a los esclavos. Véase KaPSOl., |8], pág. 53 y Alberto Flores Gal.INDO, Aristocracia y plebe, Lima, 1760-1830, Lima, 1984, cap. IV.

Las chacras (en otras partes llamadas "conucos, arboledillas o aisladitos" podian también transformarse en una forma más de explotación del esclavo cuando, al cabo de cierto tiempo, dichas concesiones pasaban a see parte de los bienes directamente aprovechados por el amo. Ermila Troconis I)I: Viracoechlis, Documentos para el estudio de los esclavos negros en Venezuela. Caracas, Academia Nacional de Historia, 1987, pág. XXXI. 
que se añadieron los costos de Justicia, lo cual deja pensar que las acusaciones de los esclavos tenían evidentes fundamentos. Pero no se trataba sino de una primera decisión que no daba por absuelto al administrador de las demás quejas y sospechas que había suscitado su manejo de la hacienda, de modo que cuando abandonó la Concepción, lo hizo esposado para ir a dar en la cárcel de Quito (11).

En este episodio, dos cosas llaman particularmente la atención: la rápida reacción de la Justicia y, hasta donde sabemos, su relativa eficacia y severidad. Estas, sin embargo, no han de extrañarnos. Poco antes de los hechos referidos, durante más de dos meses, esto es de comienzos de noviembre de 1777 hasta primeros de enero de 1778 , toda la región situada al sur del Chota-Mira había sido el teatro de una serie de "sublevaciones» y de "tumultos» indígenas particularmente violentos. El detonante había sido la aplicación un tanto acelerada e indiscriminada de una real cédula del 10 de noviembre de 1776 que ordenaba un censo general de la población. Los indígenas habían interpretado éste como una primera etapa para incluirlos en los nuevos impuestos y - según cundió el rumor entre ellos- que si se quería empadronar también a sus hijos era para hacerlos esclavos. Cotocachi, Otavalo, San Pablo de la Laguna, hasta Ibarra al Norte y Cayambe al Sur, sufrieron ataques o invasiones. Las haciendas, los obrajes y los pueblos aledaños fueron atacados, destruidos o incendiados y sus habitantes blancos o mestizos asesinados, a veces torturados. Los negros del Valle no desconocían tal situación a la que había puesto fin enérgicamente el presidente Diguja, quien que se ocupó personalmente del problema de la Concepción. Varios episodios, entre los más sangrientos, habían tenido lugar precisamente en haciendas u obrajes de las Temporalidades, pero sobre todo, enfrentando una vez más a los diferentes componentes étnicos de la colonia, las autoridades habían recurrido a los esclavos de las Temporalidades para restablecer el orden. Por ejemplo, al mayordomo de la hacienda Cuajara, se le había mandado organizar patrullas de negros para custodiar los caminos y, más tarde, una tropa de más de cien esclavos armados, procedentes de las haciendas de los expatriados y bajo el mando de un conocido nuestro, Francisco Aurrecochea, había llevado a los indígenas capturados en la región de Ibarra hasta Otavalo

(11) Expediente contra D. Francisco Aurrecoechea por maltrato a los negros de la Concepción. A.N.H.Q., Esclavos, 8. 
para que fuera juzgados y castigados (12). Se entiende, pues, que el presidente Diguja, por muchas razones, no tenía ninguna gana de ver surgir en las haciendas cañeras del Valle un nuevo foco de agitación, tanto más cuanto que el ejemplo de los tumultos indigenas y la conciencia del papel que habian desempeñado en su sofocación podian haber dejado huella entre los esclavos.

\section{CUAJARA (1783-1790): LA INESTABILIDAD Y TENSIONES ECONÓMICAS}

La reacción del administrador de la Concepción -que consistía en separar de la hacienda, a manera de castigo o en forma preventiva y cautelaria, a los esclavos díscolos o sospechososno era ninguna novedad en el mundo esclavista, ni mucho menos. Lo interesante de los casos documentados de la época en los archivos quiteños es que esta técnica represiva ya no era aceptada sin reacción por los afectados, lo cual prueba una evolución notable de la actitud de los esclavos frente a su propia situación y estatuto, así como se trasparenta también, de una manera más global, en los casos estudiados, en el artículo redactado paralelamente a éste y anteriormente referido (13).

El 19 de marzo de 1783, D. Carlos Araujo, vecino mercader de esta ciudad pidió a la Audiencia el auxilio de un piquete de soldados para sacar a algunos negros de la hacienda de Cuajara que también fuera de los jesuitas en la región del Chota-Mira. El día anterior, había ido a tomar posesión de ella con intención de llevarse a seis $u$ ocho negros jóvenes que pensaba dedicar en Quito al servicio de diversas personas y de su propia casa. Había informado de su voluntad al capitán de negros de Cuajara y, encargándole la selección, había insistido en que la hiciera con "medio suyo sin causar nobedad en la xente». El amo pensaba estar tanto más en su derecho cuanto que, según indicó después, antes de que él se posesionara de la hacienda, las Temporalidades ya habían efectuado varias extracciones de negros, lo cual, retrospectivamente, sin duda explica la actitud de éstos ante las intenciones de D. Carlos.

Al volver de sus faenas, a las seis y media de la tarde, los esclavos vinieron a saludar a su nuevo amo que los informó de su decisión. La reacción de los negros fue unánime e inmediata:

(12) MORLNO, págs. 147-196.

(13) Laval.I.E, $|6|$. 
"...todos a una boz. se opusieron, expresando que en esta hacienda trabajarian con boluntad en quanto se mandase, menos fuera de ella, ni menos el que se les saquen sus hijos porque como padres tenian dolor apartarse de ellos".

Subió tanto el tono de su réplica que, temiendo que las cosas pasasen a mayores, a $\mathrm{D}$. Carlos Araujo le pareció más prudente desistir, por lo menos de momento y en apariencia, de su intento ( «tube a bien disimularlo por no esponerme a que me faltasen al respecto»). Un testigo, Ramón Manosalvas de Ibarra, que tenía entonces un esclavo suyo trabajando en el horno de Cuajara, declaró más tarde a este propósito que éste le había confesado cómo, según afirmaban los negros, si se despachaba a algunos de ellos hacia otras haciendas del mismo D. Carlos, como San José o Puchimbuela, "ávía de correr sangre del amo y de los sirvientes". El propio D. Carlos Araujo declaró igualmente que los esclavos de la hacienda le habían quitado un negrito que el capitán le había dado para acompañarle, y al que, sin duda, sus padres no querían abandonar hacia sabe Dios qué destino.

En los documentos posteriores que D. Carlos Araujo escribió sobre este problema, que no se resolvió tan pronto ni fácilmente como hubiera querido, éste reveló que, en realidad, sus proyectos de desplazamiento de esclavos eran mayores de los que, en un primer tiempo, había confesado, pues pensaba mandar cuadrillas enteras de trabajadores a sus demás haciendas, lo que precisamente temían los esclavos de Cuajara y explica sin duda alguna su reacción inmediata.

A la inversa de lo que había pasado con el administrador Aurrecoechea, esta vez sí la Audiencia puso a disposición de D. Carlos Araujo, personaje importante y de mucho peso en la vida regional, el piquete que había pedido. Sin embargo, D. Carlos no parece haber recibido la ayuda que esperaba pues se quejó de que el oficial encargado del asunto, el teniente coronel Josef Carrasco, en realidad, no había hecho nada. Con "maña y prudencia" como él dice, el amo de Cuajara consiguió "por fin colocar a algunos negros en las otras haciendas, pero su intento llegó rápidamente a frustrarse dada la actitud de los transferidos en su nuevo destino:

Luego que los administradores y mayordomos les repreendian sus excesos, lés empreendían con violencia tirándoles a matar y promptamente regresaban a la hazienda de Guajara donde se han hecho fuertes sin que sea capás persona alguna de reducirlos a sobordinasión porque dicen, que sólo el rey, con su poder, los obligará a que salgan de Guajara. 
Dos años más tarde, la situación en Cuajara no se había aclarado y seguian enfrentadas por una parte, la lógica capitalista de rentabilidad y provecho del amo, por otra, la voluntad de los esclavos determinados a no seguir siendo meros muebles transferibles sin más en función del mercado y de los intereses del dueño.

El 9 de mayo de 1785 D. Carlos Araujo escribió de nuevo a la Audiencia. Se quejaba de que en Cuajara las dos terceras partes de los negros eran inútiles o. estaban sin trabajar. Se habían comido el ganado de las partes altas de la hacienda y "como el trapiche esta(ba) a su arvitrio viven continuamente borrachos". Ampliando su visión apocalíptica de lo que, según él, estaba pasando en su propia hacienda, D. Carlos insistía en que de manera previsible la situación se iría degradando, al punto de poner en peligro la tranquilidad pública, cosa que no podía dejar despreocupados a los oidores. Ya desprovistos de carne, los negros medio alzados se harían cuatreros y salteadores de caminos, habían de interrumpir el comercio regional y se retirarían a las alturas de donde sería bien difícil desalojarlos. Para impedir que la situación llegase a tales y tan graves extremos, D. Carlos pedía de nuevo un piquete de soldados, a los que proponía pagar personalmente, of erta cuyo objeto, sin duda, era evitar que se le opusiera cualquier argumento de tipo presupuestario. Pero en el resto de su carta, D. Carlos Araujo no vacilaba esta vez en puntualizar el motivo profundo de su solicitud. Pedía que se le concediese la plena facultad de vender a su antojo a los negros de Cuajara que juzgara necesario deshacerse. Incluso si no encontrara comprador en la región del Chota-Mira, quería poder llevarlos hasta Quito donde decidiría de su destino en función del mercado, cosas que, según D. Carlos, se acostumbraba hacer antes de que él asumiera el mando en Cuajara y que, añadimos nosotros, explican la actitud cautelaria de los esclavos en 1783.

Un detalle parece significativo. A pesar del convencimiento de estar en su derecho, D. Carlos Araujo precisó sin embargo a la Audiencia cómo, en el documento que le pedía, le rogaba no indicar que tal decisión se había tomado a petición suya y que, de ningún modo, figurase su nombre en dicho texto. El 19 de mayo, se le dio entera satisfacción (14).

No por eso quedó resuelto el problema en Cuajara. En 1788, o sea tres años después, un pariente de D. Carlos, D. Bartolomé

(14) Expediente formado por don Carlos Araujo, vecino mercader de esta ciudad, sobre que se le dé el auxilio de un piquete de soldados para sacar algunas pieras de esclavos de la hazienda de (juajará. A.N.H.Q. Esclavos 10. 
Araujo, denunció a Matías Méndiz y Solar, administrador de las haciendas de Cuajara, San José y Puchimbucla, por "la seducción de los negros" de la primera. Insistiendo, sin duda con segundas intenciones evidentes, sobre el que dicho administrador era peninsular y no criollo, D. Bartolomé le culpaba de la difícil situación por la que atravesaba Cuajara: "Se hallan más sublevados (los negros) pues en dicha hacienda no se conose sujeción menos obediencia al amo, causa la falta de buena fe». Según su acusador, Matías Mendiz habría dirigido a los negros a su antojo, consintiendo por ejemplo que el día de Santa Rosa los esclavos de otras haciendas viniesen a emborracharse en Puchimbuela o que, por motivos del casamiento de uno de ellos, unos negros de Cuajara fueran relevados de sus faenas.

Pero había algo más grave. Se reprochaba al administrador no haber cumplido con las órdenes del amo cuando éste habia mandado que se redistribuyese el personal entre sus diferentes haciendas $y$, el pasado 30 de setiembre, a raíz de una venta de esclavos a D. Melchor Rivadeneyra, Matías Mendiz habría exhortado a los negros vendidos a no trasladarse donde su comprador. D. Bartolomé reproducía las propias palabras amenazadoras del administrador. Les habría dicho: «iEa, hijos, ahora es tiempo! ¡Pararles duro sin olbidar lo que les tengo dicho!». Por supuesto los aludidos se habian negado a moverse tanto más cuanto que, por lo visto, también el capellán de la hacienda, instigado por el administrador, habría insistido a los negros «que tenían razón y usaban su derecho", actitud que tiende a revelar que el cuestionamiento de ciertos aspectos del estatuto de los esclavos, sin ser quizás amplio y profundo, tampoco se reducía, como lo habían afirmado los Araujo, a las triquiñuelas o demagogia de un administrador peninsular, codicioso e ignorante de la realidad local.

Después de tan peregrinas prédicas, ya los negros estaban "ymbuidos de que su amo no puede venderlos sin su voluntad", y, para prevenir cualquier acción de fuerza en contra de ellos, se habían retirado a las partes altas de la hacienda donde el amo no tenía siquiera la posibilidad de hablarles. Se negaban a ello y, prevenidos por el administrador, huían más sierra adentro cuando se les acercaba.

Los Araujo calificaban esa situación inaudita de levantamiento, e insistian en sus consecuencias económicas. Ya sólo se podría vender la hacienda fiada a precio rebajado, y $\mathrm{D}$. Bartolomé no vacilaba en escribir que ésta era la meta del administrador que, 
de este modo, pensaba hacerse dueño de ella (15). La Justicia sentenció sobre el asunto el 4 de julio de 1789 en un sentido no favorable a los esclavos. No sabemos qué acogida dieron éstos a la decisión de Quito, pero es fácil imaginarla así como el ambiente entonces reinante en las haciendas de los Araujo.

El 27, D. Carlos vecino de Quito pero residente en Ibarra, más cercana a sus propiedades, se enteró sobre las cuatro de la tarde de que sus negros de la hacienda San José se querían retirar de las faenas y unirse con los de Cuajara. Habiendo llegado a San José a las seis, D. Carlos fue a visitar los galpones de los esclavos que encontró en total silencio y divisó a una madre con su hija en una actitud que le pareció sospechosa ("como ocultándose»).

Las tomó de las manos con intención de ir a encerrarlas en la casa de la hacienda, pero ambas mujeres se negaron a seguirle, "armaron bulla con exageración y al mesmo passo haciéndo(le) resistencian. Con los gritos, algunos blancos de la hacienda acudieron en auxilio de D. Carlos y le ayudaron a sujetar a las dos esclavas. Pero, no bien lo habían conseguido, un nuevo incidente de mayor envergadura, e inesperado, cambió totalmente la relación de fuerzas. Según el propio testimonio de D. Carlos:

«En este inter, que no pasó ni cinco minutos, ya se havían amotinado los negros de San Buenaventura y de San Antonio del doctor Chiriboga con armas de puñales, palas y piedras, y como no me encontrasen acometieron con furor contra el mayordomo quien safó a fuerza de maña...».

Un problema nacido entre los negros de Cuajara abarcaba ahora a los de las antiguas haciendas jesuitas circumvecinas. Los amotinados rompieron las puertas de la cárcel donde estaban las dos mujeres a las que liberaron, tiraron piedras contra el amo y, por fin, habiendo alcanzado de nuevo al mayordomo, Joseph Verdesoto, le propinaron "desmedida palisa». Por su parte, considerando D. Carlos que no podía hacer nada, amenazado con un puñal y herido en una mano mientras había tratado de defender

(15) Para otro caso en que las rivalidades entre dos candidatos a la compra de una hacienda de las Temporalidades indujeron uno de ellos a soliviantar a los esclavos y a hablarles de libertad para crear dificultades a su contrincante, v. la sublevación de San Jose en el valle de Nepeña estudiada primero por W. Kapseli, op. cil., págs. 66-67, después por Tord (Javier) y Lazo (Carlos). Hacie'nda, comercilo, fiscalidady luchas sociale's (Perni colomial). Lima, Bibl. peruana de historia, economia y sociedad, 1981, págs. 215-243. 
a su mayordomo, huyó hacia Ibarra a pedir la ayuda del corregidor.

De las averiguaciones de la Justicia sobre el caso para tomar las medidas adecuadas, resultó que, en realidad, todo esto había nacido a raíz de la venta de la hacienda San José por D. Carlos Araujo, pero sin los esclavos de esta hacienda a los que pensaba transferir a Puchimbuela que también le pertenecía. Una vez más, el problema del traslado de los esclavos había sido el detonante.

La normalidad del orden esclavista tardó bastante en restablecerse. En un documento del 13 de enero de 1790, esto es medio año más tarde, el corregidor encargado del asunto escribió que los negros de las haciendas no habían vuelto a sus faenas y seguían vagando tanto en los altos como en la provincia, esparciendo así con su ejemplo peligrosos gérmenes de insubordinación.

Seis meses después, la Justicia emitió sobre el caso una sentencia definitiva. Anteriormente, para exponer su punto de vista y demostrar cómo su amo no cumplía para con ellos lo previsto por los reglamentos, cinco esclavos de las haciendas de San José y Puchimbuela habían viajado a Quito, pero dado la gravedad de lo sucedido en las haciendas, cuatro de ellos habían sido encarcelados y seguían presos. El 18 de mayo, Atanasio Olea, abogado de los Araujo, insistió en su alegato en que la meta buscada por los esclavos no era nada confesable y distaba mucho de lo que aducían en su defensa:

Ellos no han tenido otro fin que andar olgasanes, acostumbrados a no trabajar y en una vida libre qual trayan antes que don Carlos Araujo fuese a acistir en sus haziendas. Haviéndolos sugetado al trabajo, estrañaron sus pasadas anchuras.

D. Carlos Araujo era presentado como el abanderado del orden colonial, hasta como una especie de víctima de su bondad y de su voluntad de fomento de la región. No castigaba nunca a sus esclavos («no entiende de asotes»). Olea afirmaba:

La fatalidad de don Carlos ha consistido en entrar en haciendas y en gorgorrar (16) su grueso caudal en unos trapiches de negros, que le han sido muy funestos unos negros livertinos, insolentes y llenos de vicios...

(16) Absorber, consumir. Sin duda de górgoro: trago, sorbo. 
A éstos, el abogado deseaba la peor de las suertes para que, según decía, pudiesen comparar y añorar el tiempo en que habían sido de D. Carlos: «deverían estar en mano de un hombre duro y sanguinario, entonces ellos se sugetarían y cumplirían con su obligación" (17). Dada la situación, lo único que pedía ahora D. C. Araujo era deshacerse de "las cabezas del motín», y venderlas lejos del valle para que no pudiesen seguir influenciando a los demás. Por su parte, Ramón Jaramillo, procurador de los pobres en Quito - que como tal fungía de defensor de los negros- no pudo más que transmitir a la Justicia la promesa hecha por los negros encarcelados. Si el amo los aceptaba de nuevo, prometían no reincidir. En el caso de respuesta negativa de D. Carlos, para evitar que los vendiese a una hacienda alejada $y$ no tuviesen que abandonar a sus familiares y su entorno, pedian que la Justicia y Araujo los autorizase a buscarse otro amo que los comprase por un precio razonable, lo cual dado sus antecedentes, imaginamos que no había de ser fácil. Oea no desistió de su intento y siguió atacando: los negros encarcelados eran los más peligrosos. De volver al valle, "proseguirían infestando a los demás esclavos». Como era de prever, la acusación terminó ganando y $\mathrm{D}$. Carlos recibió poco después la autorización de vender a los alzados (18), pero hacía siete años que tenía que hacer frente a la resistencia obstinada de sus esclavos.

\section{LA CONCEPCIÓN (1798): El ENFRENTAMIENTO}

Por las mismas fechas, Juan Antonio Chiriboga al que aludía D. Carlos Araujo, estaba ante una situación similar. Habiendo

(17) D. Bartolomé de Araujo contra Matias Mendis y Solar sobre la sedución de los negros de las haciendas de Guajara, Autos de D. Carlos Araujo, provisión auxiliadora contra negros alsados de Puchimbuela y San José y Autos de D. Carlos Araujo contra negros huidos de sus haciendas A.N.H.Q. Esclavos, 11.

(18) Los Araujo que eran grandes propietarios esclavista siguicron apareciendo por motivos muy diversos en la crónica judicial de las causas de esclavos (A.N.H.Q. Esclavos 16). Entre estos asuntos, uno merece ser indicado aquí. En 1803, Carlos Araujo, también dueño de una mina de oro en el sitio de Malbucho situado en un afluente de río Santiago, se quejaba ante la Justicia de que, habiendo descubierto un nuevo yacimiento habia comprado 250 esclavos a un minero del Chocó, el doctor D. José Miguel de Rivas. Sin èmbargo, la transacción no pudo realizarse "porque los negros resistieron la meditada extración, sucediendo lo mismo con otro contratos posteriores". Estas palabras prucban a las claras que la actitud de resistencia de los esclavos ante su traslado a otros centros de trabajo que notamos en el Chota-Mira no era nada peculiar de dicha zona... D. Carlos Araujo tuvo que mandar a su hijo hasta Lima y Panamá para comprar alli una cuadrilla de borales (Ihid). 
comprado la hacienda de la Concepción con fianzas muy elevadas, había conseguido la autorización de vender, en compensación, unos esclavos... y "demás muebles que reconociese sobrantes». Negándose a esto, diecisiete negros se habían encaminado (huido según el amo) a Quito para impedirlo pero, esta vez, como sus argumentos habían parecido infundados o insuficientes, la Justicia los había encarcelado. Juan Antonio Chiriboga se aprovechó entonces de la situación para vender, con el beneplácito de la Administración a "los más reboltosos e ynquietos" esto es a los diecisiete, destinando en principio el producto de la venta a las Cajas Reales. Como J. A. Chiriboga había negociado con un trapichero de Tumbaviro que, a cambio de los esclavos, le había cedido otra hacienda, ésta fue incluida en las hipotecas de J. A. Chiriboga... (19).

Varios años después, en 1798, Juan Antonio Chiriboga y sus esclavos de la Concepción iban a protagonizar el problema más grave que habían de conocer por esos años las haciendas del Chota-Mira. El 21 de junio, estando en Ibarra donde ejercía sus funciones de alcalde, J. A. Chiriboga recibió "un expreso" donde su esposa le anunciaba que, desde el día 18, los negros de la Concepción estaban sublevados "sin el menor motivo" y se habían retirado al monte a una o dos leguas de la hacienda. J. A. Chiriboga salió en el acto a averiguar el caso.

En el documento que sobre esto escribió sin tardar, el 22, al otro alcalde de Ibarra Pedro Terán, explicaba cómo casi todos los esclavos se habían retirado en las alturas de la hacienda, llamadas el Hato de la Cocha, donde "están asiendo los maiores desastrosos daños y perjuicios, robándose no sólo el ganado sino quanto encuentran». Deseoso de reducir a los alzados por las buenas, J. A. Chiriboga les mandó sucesivamente cuatro recados suaves por sendos mensajeros: primero, un negro, Antonio Chala, de los pocos fieles, que fue a buscar un hijo suyo, pero después, de apresarlo y maniatarlo, los rebeldes le quitaron los calzones y lo devolvieron así a la hacienda no sin propinarle una buena paliza ("que lo sobaron entre los alsados»); luego, otro hijo de

(19) A.N.H.Q. Esclavos 12. Un dato anterior pero muy significativo y esclarecedor para el problema que estudiamos está en un documento de $1787^{\text {(A.N.H.Q. }}$ Esclavos 11). Ese año, un tal D. Josef Olavarri, de Popayán, había propuesto a las Temporalidades comprar por 11203 pesos a 43 esclavos de la Concepción. La respuesta de Quito fue negativa en la medida en que el administrador de la hacienda, Manuel de Ameraga, indicó que allí, dadas anteriorés extracciones, sólo quedaban tres cuadrillas notoriamente insulicientes para el trabajo hasta tal punto que a veces él se véa én la precisión de utilizar lambién para las faenas a los muchachos. 
Chala que salvó la vida por milagro, esto es a la presencia de un pariente suyo; después, la mujer y madre de los precedentes que fue apresada; por fin, un indio al que "quasi aorcan" ya que su amo le había mandado allá a recuperar un caballo que los negros se habian robado "para correr y comerse el ganado".

Ante la inutilidad de tales embajadas, el capellán de la hacienda y coadjutor del anejo se atrevió a subir al Hato acompañando al tenedor de libros de la Concepción, Mariano Bergara, un hombre de toda confianza para J. A. Chiriboga al que servía desde hacía catorce años, y a dos negros leales, el capitán y un esclavo carpintero que, él también quería convencer a uno de sus hijos de volver a la hacienda, como va antes lo habían hecho, sin éxito, varios esposos deseosos de recuperar a sus mujeres que habían huido a las alturas:

Se fueron para persuadirles con suabidad y rasones que, no aviendo motivo alguno, isiesen tales temeridades, pero con todo les prometieron serían perdonados si se recogiesen a la hazienda buenamente.

La respuesta de los alzados fue rotunda, y las mujeres allí "agavilladas" dieron la señal de la arremetida lanzando piedras y excitando a los hombres (20)

Se alteraron con tanta desbergüença que, sin respetar al sacerdote de quien se abrasó el negro fiel le irieron a éste con una lansa y le dieron un machetaso en el braso que parece estar liciado y el escribiente se escapó de una lansada que sólo le atravesó la ropa.

Efectivamente, Bergara contó después ante la Justicia cómo evitó milagrosamente una lanzada que le perforó el poncho y el chaquetón y recibió una tajada en el sombrero mientras el negro que le acompañaba quedaba malherido, con una lanzada en el quadril cuyo impacto se agravó por la violencia con que su agresor, Inocencio Quiteño, le arrancó el hierro del cuerpo. En su carta, J. A. Chiriboga insistía en sus temores de que la llamada sublevación tomara maior incremento y recelaba "funestas consequencias y la pérdida de esta hazienda». Considerando que la Corona tenía «el maior interés por el amparo de las Temporali-

(20) Para el papel importante de las mujeres en semejante's casos, v. Kapsoli [8], pág. 59. 
dades", cuya hacienda, dadas las circunstancias, según afirmaba, va no tenía sino la décima parte de su valor, Chiriboga instaba a su colega alcalde a que pidiese el Real Auxilio y, mientras llegase éste, se personase en la hacienda con algunos mozos de Mira «pues esta administración de justicia es la más urgente en el día para remitir la actuación al Superior Gobierno o a la Real Audiencia».

En su testimonio sobre los hechos, el capellán, F. Jacinto Carabaca, explicaba cómo habiendo ido al monte para anunciar a los negros la inminencia del perdón, los encontró en actitud levantisca e irreverente, "sentadotes" en un pocito del que, cuando se les acercó, no se dignaron levantar hasta que pronunciase el nombre de Dios: Dejémosle la palabra:

"Les dije quanto pude, haciéndoles un relato patético y combinsente sobre que no tenían motivo para haverse alsado pues ninguno de ellos havía llebado ni un asote en esta temporada".

Cuando en su conclusión los exhortó a que bajasen con él y volvieran a la normalidad, se insolentaron todos, gritaron repetidas veces «itraición, traición!». Embistieron con lanzas, machetes, hachas, palas y piedras contra el negro Eduardo Borja que acompañaba al fraile y se agarró de él. Cayeron ambos de rodillas y, mientras F. Jacinto, con los brazos abiertos, clamaba al cielo y pensaba morir, los esclavos se ensañaron contra el capitán de negros que iba con el religioso, lo que dio tiempo al fraile para escapar ("y en el interin que chocaba éste con aquellos, tube tiempo de huir y nos escapamos").

Por su parte, J. A. Chiriboga pidió al alcalde de Ibarra que hiciese una investigación sobre los hechos. Propuso que los testigos contestasen nueve preguntas que todas concernían el trato dado a los esclavos de la Concepción y tenían obviamente como fin demostrar la total ausencia de justificación por parte de los negros así como, paralelamente, la buena fe y humanidad de su amo.

El resultado fue conforme con lo previsto. El 24 de junio, las respuestas suscritas por los declarantes - vecinos de la Concepción, empleados de J. A. Chiriboga y aún esclavos de éste- se encaminaron todas a lo mismo, esto es demostrar sobradamente lo que se esperaba de ellos y quería el dueño de la hacienda. No obstante, en sus declaraciones se pueden espigar no pocos detalles 
muy significativos, tanto para el problema en sí como para la vida de la época en aquellas haciendas del norte quiteño.

Primero, es de notar que, sin darse cuenta, en el mismo texto de las preguntas redactadas por el propio J. A. Chiriboga deseoso a la vez de exculparse y de denunciar las sinrazones de sus esclavos, éste que en su primera carta a la Justicia de Ibarra había insistido en que "casi todos" los negros estaban alzados, puntualizaba ahora que tan sólo sesenta de ellos -esto es una pequeña minoría - habían huido al Hato de la Cocha, lo cual, de hecho, reducía el motín, como lo llamaba Chiriboga, a otras proporciones.

Todos los declarantes afirmaron con un gran lujo de precisiones que, en tiempos de los expatriados y de la administración de las Temporalidades, los esclavos estaban tratados peor que en la actualidad. Pablo Villegas, que se había criado en la hacienda, recordaba cómo entonces, al llegar a la Concepción, cada esclavo recibía de entrada 200 ó 300 azotes sin contar otros recios castigos, y el propio Antonio Bergara precisaba que los jesuitas pegaban a sus negros "por antojo", y propinaban cincuenta azotes por cualquier sustración de instrumento perteneciente a la hacienda.

En otros momentos, los testigos insisten sobre la benignidad del trato de J. A. Chiriboga: daba a cada uno de sus esclavos un sombrero, rebozos de Guano con dos trajes al año en vez de uno en tiempos de los jesuitas y, para tal efecto, tenía un sastre a sueldo en la hacienda. Mariano Bergara describe detalladamente esa vestimenta, que también se daba, precisa él, a viejos y niños, esto es a aquellos que no trabajaban, y cuenta cómo se repartía a los negros sal, tabaco y carne cada semana, lo que los padres sólo hacían en tiempos de faenas.

Estas y los castigos eran ahora moderados. Mariano Ximenez, otro testigo, discrepaba un tanto al respecto indicando que había escuchado al uno y al otro que los trabajos eran excesivos, pero se apresuraba en añadir que sabía que el amo no estaba enterado de ello... Sin embargo, bien parece que el problema laboral estuvo en el centro de la sublevación. José Bonifacio declaró así que ésta había estallado al día siguiente que se mandase a los esclavos limpiar la acequia de la hacienda. Otros testigos revelan que, desde algún tiempo a esa parte, las relaciones estaban bastante tirantes en la Concepción. Confirman la existencia de otra retirada de los negros a los altos de la hacienda cuando el administrador precedente, Andrés Salvador, así como el hecho de que algunos negros habían ido anteriormente a quejarse ante la justicia de 
Ibarra e incluso ante la de Quito, cosa que Chiriboga, que también aludia a ella, censuraba enérgicamente pues se iban: "con quejas fingidas con el objeto de osiosear y benir más insolentes engañando a los jueses".

Plenamente respaldado por sus testigos, Chiriboga escribió a la Justicia de Quito dos días después, el 26, pidiendo con la mayor brevedad el auxilio que necesitaba para restablecer el orden, a su parecer destruido durante la administración de las Temporalidades cuyos funcionarios, encargados cada uno de varias haciendas a las que consideraban como ajenas, habían manifestado bastante dejadez. Primero, el amo pintaba su situación de manera muy lastimera:

"Auxilios no tengo cómo reprimir la furia de estos insolentes negros, la vida la tengo en peligro casi ebidente, ni tampoco me atrevo a desamparar la hazienda porque no caiga en su total ruina y tal vez se pretenda aserme cargo de ella».

A continuación, por si el sentido de su pedido se le hubiera escapado al presidente de la Audiencia, pedía un castigo ejemplar:

"Aunque sea a costa de alguna sangre en caso necesario, se ataje o reprima a estos bárvaros o se prendan las cavesas del motín o que sean bendidos a su precio puesto en Temporalidades y como la hidea de ellos, según se an significado, es que no an de sosegar entre tanto que la hazienda no buelva a ser de Temporalidades, ya verá Vuestra Alteza la extravagancia de este modo de dispensar y otras ridiculeses que sería molestar a Vuestra Alteza el referirlas. Pero no será de más el descubrir el fin de la hidea".

Según Chiriboga, la culpa la tenía la administración de las - para él_ funestas Temporalidades:

«En lo espiritual vivían en un libertinaxe de escandalosos adulterios, camviados de mugeres, obsenidades espantosas de estrupos y borracheras y otros delitos... a este modo de vida an estrañado el que yo y mi hijo D. Josef Valentín ubiéssemos çelado por la onrra de Dios semejantes absurdos, p:ro no tanpoco con un selo amargo ni imprudentes sino con la suavidad prevenida por nuestra Ley".

Pero ya no era tiempo de filosofear e, interrumpiendo sus reflexiones sobre el pasado, J. A. Chiriboga terminaba insistiendo 
sobre el hecho de que "la ingencia del caso presente no permit(ia) tan prolixo discernimientom. En otras palabras habia que actuar.

Los testigos habían declarado el 24, D. J. A. Chiriboga escribió el 26. El 28, en Quito, el abogado agente que hacía de fiscal dio su parecer pues un asunto de tanta gravedad exigía una reacción inmediata. El representante del Estado puntualizó que había que cortar por lo sano antes que tom(ase) cuerpo esta sublevación que puede tener fatales consequencias a todo el público. Encargó al alcalde Terán que redujese y castigase sin demora a los alzados (castigándoles el delito y volviéndoles a poner en la servidumbre a que deben estar sujetos) y, para tal efecto, podría acudir al auxilio del corregidor de Ibarra.

Quedaba por resolver el problema de los gastos previsibles de la vuelta a la normalidad. El dueño, o en su defecto la Real Hacienda, se haría cargo de la quinta parte de ellos mientras el resto, según una fórmula vaga, se repartiría entre aquellas personas que tuvieran interés en esta pacificación - esto es los demás dueños de haciendas de la zona- para que:

"de este modo, atajándose el mal en el prinsipio no tome cuerpo, de suerte que el mal exemplo no contamine a las otras haziendas de esclabos y no se ponga todo en desorden, que puedan originarse robos, muertes y otros delitos que cometieron los negros simarrones y levantados si no se reducen prontamente y no son castigados como lo pide el casom.

Sin más dilación, el alcalde Terán se encaminó a la Concepción. Su intención era capturar a los cabecillas y venderlos lejos de la región como se lo había pedido J. A. Chiriboga. Según contó el alcalde, el plan previsto funcionó perfectamente, por lo menos al principio. Los negros bajaron de los altos, pero cuando sospecharon el castigo que podía esperar a algunos de ellos, amenazaron con volver en seguida al Hato de la Cocha, lo cual hubiera desbaratado el plan. El alcalde olfateó esa posible reacción e hizo todo lo posible, según dijo, para que los esclavos no entendiesen su designio. Delegó a los altos de la Concepción al teniente de alguacil mayor con la orden de regresar con los cinco más insolentes para que compareciesen en Ibarra, pero cuando llegó allí no estaba nadie para esperarlo y tuvo que volver a Ibarra donde Terán decidió ir personalmente hasta los altos donde acampaban de nuevo los esclavos. Lo acompañaba el teniente de alguacil mayor pero, por si acaso y para ser más 
convincente, nada menos que 23 mozos nobles, esto es de la aristocracia esclavista de Ibarra.

Al llegar a la altura, se les presentaron todos los negros allí retirados, y cuando el alcalde les conminó a que volviesen a la Concepción, se negaron rotundamente a ello (lo resistieron con obstinación) haciendo significativamente hincapié en que no volverían a la hacienda mientras ésta no fuera devuelta a la administración de las Temporalidades. Indicaron que si se habían regresado a las alturas era porque estaban perfectamente al tanto de que Chiriboga iba a vender a algunos de ellos. Pensando reducirlos por el hambre o, por lo menos, queriendo hacerles más difícil o tal vez imposible la permanencia en las alturas, el alcalde dio entonces a los mozos que iban con él la orden de quitarles el ganado. Los negros intentaron oponérseles, tirándoles piedras y echaron mano de las armas que traían. Pero la refriega les fue rápidamente adversa dado que, sin duda, los mozos nobles venían fuertemente pertrechados. Tres de ellos dispararon escopetazos de plomo menudo a los negros de lo cual resultaron levemente heridos dos esclavos, uno en la cara el otro en una pierna, mientras que los demás mozos conseguían bajar con los animales.

Aprovechando la noche, muchos de los alzados, según Terán, bajaron hacia el valle y siguieron hacia Quito donde se escondieron esperando así burlar la persecución de la Justicia. Haciendo el balance del encuentro, el alcalde insistía en que La Concepción había sufrido, y no sólo en lo material, daños de consideración de los que tardaría mucho en recuperarse, de modo que concluía su relación de lo sucedido con las acostumbradas amenazas de castigo y expatriación, pero también con algunas advertencias muy interesantes sobre el ánimo de la gente de Ibarra frente a los negros de las haciendas:

«Necesita el más pronto y eficaz reparo como de un exemplar que sea bastante a contenerlos en lo sucesivo a éstos y a los de las demás haciendas que a su imitación tardarán poco en cometer estos excessos y mayores, aunque para hacerlo no tengan el menor motivo para pretexto como no lo ha habido en las presentes circunstancias. Acá no hay fuerzas competentes para dar auxilios correspondientes para castigar o expulsar a los que conviene, porque a los de la plebe que se pueden llevar tienen un terror pánico a los negros. Estos creen que la comición es fingida y sea por esso o por su altanería se han burlado y me han perdido el respeto...". 
Poco a poco se restableció el orden esclavista en La Concepción. J. A. Chiriboga llegó a sus fines. En la carta que mandó, en conclusión, a la Real Audiencia indicó que había escogido el arbitrio más suave: había vendido a algunas "cabezas del motín, creiendo ser suficiente ejemplar para que los demás se sosegasen y escarmentasen. Y para que se aga el exemplar que satisfaga la vindicta pública, tengo arbitrado - añadía- bender tres o quatro pares más de los mesmos que an sido cavesa del motín y que se allan en la cárcel de esta ciudad", esto es Ibarra.

Sin embargo, conocedor de la realidad regional pero sin duda queriendo también insistir interesadamente sobre los problemas que le esperaban, J. A. Chiriboga preveía que este proyecto no se realizaria tan fácilmente. Sin ayuda exterior, no podría conducir a dichos esclavos donde su nuevo amo, el doctor Juan Cruz Castillo dueño de una hacienda en las inmediaciones de Ibarra. Pensaba hacerlo con algunos hombres de su confianza pero también con un piquete de cinco soldados cuya colaboración pedía a la autoridad competente. Pero a esto no se había de reducir la misión de la tropa. A la vuelta, ésta le ayudaría a sacar de La Concepción "a las consortes de los nominados que con malicia estudiada se ha(bían) quedado en la hazienda" sin duda para motivar legalmente un eventual regreso. En cuanto a los demás implicados, Chiriboga los pensaba castigar con latigazos en número variable según la gravedad de lo que se les podría probar.

Quedaba el caso de los encarcelados - no se dice si en Quito o en Ibarra-. Estaba dispuesto a acogerlos en La Concepción aunque, sin duda por diversas razones no los necesitaba ya. Pero J. A. Chiriboga pensaba que con tan sólo aceptarlos de nuevo les hacía tan señalado favor que estarían dispuestos a aceptarlo todo:

"Con sólo desirles que se baian a ella (la hacienda) lo arán sin desviarse i más después de darles un moderado castigo en la cárcel, como lo suplico a Vuestra Merced a que baian sin miedo de más castigo porque, faltándoles la sugeción de los que los an inquietado o influido mal, no se of rece recelom.

Volviendo al caso de los tres o cuatro pares de esclavos a los que pensaba vender, J. A. Chiriboga indicaba que estaba decidido a enviarlos a Guayaquil, esto es bien lejos del Chota. Ya un sujeto de confianza se había comprometido a llevarlos. El precio de la venta se destinaría a las Temporalidades y serviría a cance- 
lar parte de las deudas que el dueño de La Concepción seguía teniendo pendiente con ella (21).

En su ya citado estudio sobre las haciendas que habían sido de los jesuitas en el valle peruano de Nepeña, queriendo calibrar de la manera más justa posible a la vez lo que había sucedido allí y su posible proyección posterior, Javier Tord y Carlos Lazo analizan detenidamente si, de acuerdo con la terminología oficial de la época, dichos hechos fueron realmente, como afirmaban interesadamente los amos, motines, sublevaciones o tumultos. Para este aspecto de los casos del Chota-Mira, que acabamos de ver, remitimos a lo que acertadamente escriben los dos historiadores peruanos en dicho artículo.

De momento, y pensando en el otro trabajo nuestro concebido paralelamente a éste (22), nos parece de mayor interés subrayar más bien cómo las diferentes actitudes de los esclavos que hemos notado, distaban mucho de ser, por una parte, meras reacciones primarias de rebeldía contra la esclavitud, por otra, intuiciones revolucionarias. Si bien carecieron de carácter espectacular, por su naturaleza colectiva pero también por forma iterativa, su pertinacia y su matización, más que brotes de exasperación sin alcance ni porvenir, de manera evidente nacen de un cuestionamiento real de la institución esclavista. No se trataba de un rechazo de ésta en sí ni de forma conceptual, pero es significativo que en las actitudes de los negros chotanos ciertas prácticas tan viejas como la misma esclavitud ya no parecieran aceptables y se juzgaran, por los mismos esclavos, como abusos insoportables.

Dicho de otro modo, los sucesos del Chota-Mira, como no pocas actitudes y alegatos conservados en la documentación quiteña de la época sobre negros, revelan que la esclavitud estaba sufriendo, en los hechos y en las mentalidades, evoluciones quizás entonces poco perceptibles pero indudables desde la perspectiva del análisis histórico. La esclavitud se encontraba de hecho bastante restringida si, como lo defendían los esclavos del Valle grande, los amos ya no podían traspasarlos como meros bienes muebles, lo que eran legalmente, si no los podían "desnaturalizar», esto es obligarlos a mudarse de lugar y de entorno. Los amos

(21) Expediente de D. Juan Antonio Chiriboga en que cuenta la sublevación de los negros de la hacienda de la Concepción en la jurisdicción de la villa de Ibarra, año de 1798 (A.N.H.Q. Esclavos 15).

(22) LAVAI.I.1., [6]. 
creian que se podria seguir haciendo lo de siempre y que su dominación continuaria omnimoda, los afectados, ellos, en su resistencia ya demostraban, y de muchas maneras, espectaculares unas, casi imperceptibles otras, pero todas concientes, que los tiempos habian cambiado y que la esclavitud había entrado por fin en su - larga - fase de descomposición. 